\title{
Fabrication of High Flux Polysulfone/Mesoporous Silica Nanocomposite Ultrafiltration Membranes for Industrial Wastewater Treatment
}

\author{
Mohamed E.A. Ali ${ }^{1(\mathbb{D})}$, Ahmed Shahat ${ }^{2, *(\mathbb{D})}$, Tamer Irfan Ayoub ${ }^{3, *(\mathbb{D})}$, Rasha M. Kamel ${ }^{4}$ \\ 1 Egypt Desalination Research Center of Excellence (EDRC) \& Hydrogeochemistry Department, Desert Research Center, \\ Cairo, 11753, Egypt; m7983ali@gmail.com (M.E.A.A.); \\ 2 Department of Chemistry, Faculty of Science, Suez University, Suez, Egypt; ashahat@aucegypt.edu (A.S.); \\ 3 Suez International Nitrate Company (SINCO), Suez, Egypt; Tamer.Irfan @ yahoo.com (T.I.A.); \\ 4 Department of Chemistry, Faculty of Science, Suez University, Suez, Egypt \\ * Correspondence: ashahat@aucegypt.edu (A.S.); Tamer.Irfan@yahoo.com (T.I.A.);
}

Scopus Author ID 36143273100

Received: 16.10.2021; Revised: 15.11.2021; Accepted: 17.11.2021; Published: 25.11.2021

\begin{abstract}
The inclusion of nanosphere particles like mesoporous silica MSNS 500(nm) inside the membrane substance matrix substantially enhanced water permeability and dye rejection. The dry/wet stage conversion method was employed for fabricating all membranes. The influence of different concentrations for MSNS (0-8\% wt.\%) in the existence of povidone (PVP) acting in the role of poreforming on the behavior of the PSF-UF membrane was investigated. Results revealed that as soon as MSNS level grew up till 6 wt. percent, the rejection of Methylene blue (MB) dye gradually increased. The morphological properties of UF-produced membranes $\mathrm{PS} / \mathrm{PVP} / \mathrm{SiO}_{2}$ were investigated using scanning electron microscopy. They demonstrated a considerable degree of MB rejection of 84.7 percent, as well as an increase in MSNS concentration to 6 wt. percent. Besides, as the MSNS concentration raised to $6 \mathrm{wt} . \%$, the membrane's permeability dropped from $429.2 \mathrm{~L} / \mathrm{m} 2 . \mathrm{h}$ for PS/PVP to $136 \mathrm{~L} / \mathrm{m} 2 . h$ for $\mathrm{PS} / \mathrm{PVP} / \mathrm{SiO}_{2}(6 \%)$ membrane. Only water was permitted to pass across the hydrophilic UF fabricated membrane on the feed side, improving the quality of the water stream on permeate portion, making the fabricated membranes appropriate for industrial treatment of wastewater. The addendum of the polyvinylpyrrolidone acting as an additive to the investigated membranes enhanced their efficiency.
\end{abstract}

Keywords: ultrafiltration; dye removal; mesoporous silica; wastewater treatment.

(C) 2021 by the authors. This article is an open-access article distributed under the terms and conditions of the Creative Commons Attribution (CC BY) license (https://creativecommons.org/licenses/by/4.0/).

\section{Introduction}

Water's importance in humanitarian existence cannot be emphasized, as it is necessary for various activities involving home usage, recreation, power generation, agriculture, and industry. With a rising need for water fit to drink, more recent observations have been made concerning water treatment [1]. Dyes are extremely utilized in both textile and dyeing processing. Synthetic dyes are produced in excess of 0.7 million tons per year across the world [2]. In addition to wasting a lot of chemicals and water, releasing improperly processed textile waste into our environment may cause many health and environmental problems. By traditional treatment procedures, most dyes are poisonous and organic-carcinogenic, including physiologically resistant to breakdown or degradation, owing to their complex aromatic ring structure. As a result, it's critical to develop a technique for effectively removing these colors 
from effluents. There is now a large number of biological, chemical, and physical methods for removing colors from effluents. However, each has its own set of benefits and drawbacks. $[3,4]$. Membrane separation techniques are the best cost-effective, highly selective, and quick to combine with other operations of all traditional and innovative wastewater treatments [5] [6]. A compact footprint and no phase change during the segregation procedure are further advantages [7]. Ultrafiltration (UF) is frequently employed to separate, purify, and concentrate water-soluble solutes or water-dispersible compounds [8].

Polysulfone [PS] is a popular material employed to manufacture UF membranes for a series of purposes like segregation of gas, beverage, processing of foodstuff, and treatment of wastewater [9]. The polymer simplifies membrane manufacture owing to its mechanical strength, chemical inaction, good layer forming capabilities, adjustable pore size, thermal constancy, and repeatable features [10]. The failure of manufactured membranes to reject or adsorb tiny molecules, or the membrane's hydrophobic nature, necessitates this. To compensate for the incapability, organic/inorganic chemicals or nanomaterials can be introduced as a third dimension to the membrane's dope solution. Other widely used additions include polyvinylpyrrolidone (PVP), polyethylene glycol (PEG), propionic acid (PA), polyethylene oxide (PEO) in addition to surfactants, alcohols, and water [11-13]. Since ultrafiltration became a feasible industrial technique in the 1960s, thousands of dissimilar ultrafiltration fabricated membranes have been commercially available. Different UF membrane producers are listed, several of which manufactured many different series of membranes (e.g., renovated cellulose, polysulfone, and cellulose acetate), each membrane-containing sequence with a changed molecular wt. cut-off or size of pores Owing to their high water solubility, organic solvents, little toxicity, complexing performance, and strong film-forming characteristics, UF produced membranes by a conversion phase method are extensively utilized by means of polymers soluble in water like poly(ethylene glycol) and poly(vinyl pyrrolidone) [14]. The pores of those water-solvable polymers tend to improve both of pores and porosity of the membrane surface $[13,15,16]$.

Nanomaterials remain, in fact, a connection between atomic or molecule structure and bulk material structure [17]. The membrane permeability, antifouling characteristics, and mechanical qualities have increased recently, which has had a major impact on the casting solution. Nano-blending nanofibers, for instance, silica, silver, titanium nanoparticles, carbon nanotubes, and polyaniline (PANI) nanofibers, were used in UF membranes [18-24]. The number of tiny holes and membrane porosity rises when a sufficient nanomaterial is introduced, whereas membrane pores lighten across the cross-sectional structure. Furthermore, unlike water-solvable polymers advantageous to membrane stability, nanoparticles might persist in the produced membrane eternally as an additive. The supplement of a modest spectrum of nanomaterial might result in a considerable increase in membrane permeability [25]. Nanomaterials, on the other hand, agglomerate owing to their enormous specific surface area. Agglomeration shrinks the value of nanoparticles for enhancing membrane execution, which has a detrimental influence on the successful usage of nanomaterials in nanocomposite membranes [22]. Two approaches have been attempted to combat nanomaterial agglomeration: mechanical dispersion (sonication and grinding) and chemical nanomaterial surface modification. We employed sonication to break up the clumping of MSNSs in this work $[22,26]$.

Mesoporous silicas in form like [SBA-15] and [MCM-41] are solid materials incorporating a honeycomb-like porous construction with hundreds of vacant channels. Just 
recently, mesoporous silica nanoparticles (MSN) have been carefully explored in materials research because of their novel properties, like extensive surface areas, big pore volumes, convergent pore sizes with a narrow distribution and tunable diameters of particles demonstrated the biocompatibility, the high constructional stability and chemical fluctuation of silica using semiconductor quantum dots coated with silica. Also, the bio disintegration of silica nanospheres has been established in mice. MSN by means of conditioned properties can be employed for a broad range of uses, for example, delivery of drugs, catalysts backings, separation of proteins, cell imaging, cell marking, adsorption of enzyme and optical detection, and adsorption of vanadium (V(II)) ions in wastewater samples [27].

Searchers are incessantly involved in efforts to come up with cushy methods for preparing MSN with controlled properties, like, smaller particle sizes, tunable pore diameters, high surface area, and high pore volumes [28]. The usage of additional reagents, like pore expanders and/or the usage of surfactants with varying chain lengths are the generally used methods for tuning MSN properties. However, changing the ratio of reagents concentration in a typical reaction mixture to obtain the same or better results would be cheaper and easier[29].

In this work, we increased the hydrophilic character of PS ultrafiltration membranes by consuming mesoporous silica, which raises the selectivity and continuity in the method of membrane ultrafiltration, creating new pores suitable for rejection of Methylene blue $\mathrm{C} 16 \mathrm{H} 18 \mathrm{ClN} 3 \mathrm{~S}$ Molecules in addition to the cohesiveness of membrane matrix. On the other hand, to improve membrane performance, polymers soluble in water, such as poly (vinyl pyrrolidone) (PVP) was used.

\section{Materials and Methods}

\subsection{Materials.}

Udel® P-3500 LCD MB Polysulfone (PS) provided by SOLVAY Advanced Polymer Company was handled as polymer materials. Such as solvent, N, N-dimethylformamide (DMF) with analytical pureness of $99.5 \%$ was obtained from Merck, Germany. Cetrimonium bromide, known as (CTAB), tetraethyl orthosilicate (TEOS) were bought from Sigma-Aldrich. Poly (vinyl pyrrolidone) (PVP) 40,000 was bought from LOBA Chemie. Methylene blue, C16H18CIN3S, was purchased from Oxford Lab Fine Chem LLP.

\subsection{Mesoporous Nano Silica Spheres preparation.}

At normal temperature, hydrolysis of TEOS with a catalyst of ammonia in a mixed solvent of $\mathrm{H} 2 \mathrm{O}$, diethyl ether, and acetone was employed to create mesosphere particles of silica utilizing silica CTAB as a term tablet. CTAB $(0.5 \mathrm{~g})$ was typically mixed in of Milli-Q water $(100 \mathrm{ml})$ then agitated for 30 minutes before adding up acetone $(40 \mathrm{~g})$ and stirring for 30 minutes before adding diethyl ether $(20 \mathrm{~g})$. After 30 minutes of stirring vigorously, TEOS $(2.5$ $\mathrm{mg}$ ) was added and swirled for another 30 minutes, followed by $1.5 \mathrm{~g}$ of $\mathrm{NH}_{3}$ (25 wt. percent). For 24 hours, the gel was strongly agitated in a sealed jar at site temperature. Filtration was employed to capture the particles, washed using deionized water, and then dried at $80{ }^{\circ} \mathrm{C}$ for 24 hours. Then calcination from site temperature till $550{ }^{\circ} \mathrm{C}$ for 4 hours, continued by another 8 hours at $550{ }^{\circ} \mathrm{C}[30]$. 


\subsection{PSF-UF membrane preparation.}

The standard phase conversion approach was employed to prepare all PS-UF membranes. In brief, the neat PS (M0) was dissolved in (15 wt.\%) DMF and rapidly agitated for $6 \mathrm{~h}$ to reach a homogenous and clear mixture. PS/PVP membrane (M1) was prepared by dissolving 2.4 wt. percent PVP $(\mathrm{Mw}=40,000)$ in DMF with gentle agitation until a clear homogenous solution was produced. Different amounts of silica nanoparticles $(2,4,6$, and 8 wt. percent) were dispersed in the casting solutions for the preparation of $\mathrm{PS} / \mathrm{PVP} / \mathrm{SiO} 2$ membranes and coded as M2, M3, M4, and M5, respectively (Table 1), and then ultrasonication for the mixture for 30 minutes at $(30 \mathrm{kHz})$ frequency to ensure a high dispersion of $\mathrm{SiO} 2$ nanoparticles [31]. All polymer solutions were degassed at site temperature for 24 hours before being cast onto a clean/dry glass tablet with a knife applicator with a $200 \mu$ perfect gap involved between the applicator knife and the glass tablet. Defect-free membranes were obtained by soaking the tablet in a clean water bath for an extended period and then washing it with deionized water before characterization and membrane performance testing [12].

Table 1. Composition of casting solution used for the preparation of nanocomposite membranes.

\begin{tabular}{c|c|c|c|c}
$\begin{array}{c}\text { Membrane } \\
\text { code } \\
\text { number }\end{array}$ & $\begin{array}{c}\text { PS } \\
(\boldsymbol{\%})\end{array}$ & $\begin{array}{c}\text { MSNs } \\
(\boldsymbol{\%})\end{array}$ & $\begin{array}{c}\text { PVP } \\
(\boldsymbol{\%})\end{array}$ & $\begin{array}{c}\text { DMF } \\
(\boldsymbol{\%})\end{array}$ \\
\hline $\mathrm{M}_{0}$ & 15 & 0 & 0 & 85 \\
\hline $\mathrm{M}_{1}$ & 15 & 0 & 2.4 & 82.6 \\
\hline $\mathrm{M}_{2}$ & 15 & 0.3 & 2.4 & 82.3 \\
\hline $\mathrm{M}_{3}$ & 15 & 0.6 & 2.4 & 82 \\
\hline $\mathrm{M}_{4}$ & 15 & 0.9 & 2.4 & 81.7 \\
\hline $\mathrm{M}_{5}$ & 15 & 1.2 & 2.4 & 81.4
\end{tabular}

\subsection{Characterization of mesoporous silica nanospheres.}

A PerkinElmer Lambda 950 model solid-state UV-vis spectrophotometer device was employed to capture the absorption spectra of the mesoporous chemosensor. (SAXRD) Small degree angle technique X-ray deflection images were gained via the XPERT - PRO PANalytical, (WAXRD) wide degree angle technique X-ray deflection images were acquired via the Bruker D8 Discover diffractometer together with monochromated. Adsorption besides desorption data determined at $77 \mathrm{~K}$ by means of Quantachrom Autosorb technique. Before testing, the samples were outgassed for 24 hours at $80{ }^{\circ} \mathrm{C}$. N2 adsorption data was employed to define the [BET] surface zone areas and pore volumelsize allocation. The allocations of pore extent size were evaluated by the Barrett-Joyner-Halenda (BJH) technique on the adsorption branch of the nitrogen isotherms. Images were captured by means of a Zeiss Leo Supra55 microscope and (FESEM) field emission scanning electron microscopy. The samples for FESEM examination were not coated with any metal. For depiction, crystal construction, and elemental study, a high-resolution microscope (HR-TEM, Tecnai G20, FEI, the Netherlands) was employed.

\subsection{Membranes characterization.}

Earlier to characterization, the materials were vacuumed with drying for 24 hours at 40 degrees Celsius. The tangency angle between water and membranes was measured using the sessile drop technique Kruss model DSA25B to evaluate their water wettability [32]. Via drops of 8.0 0.21 volume were dropped on the surface of the membrane by a Hamiltonian syringe, and pictures were captured with a delay of $5 \mathrm{sec}$. The contacting angles were then calculated 
by means of the drop snake technique [33]. In the $500 \mathrm{~cm}^{-1}$ to $4000 \mathrm{~cm}^{-1}$ range, the Fourier Transform IR type spectroscopy technique (FT-IR). (Thermo scientific Corp., Nicolet iS50, USA) was utilized. The morphologies of surfaces besides cross-sections of the manufactured membranes were examined using (SEM- Quanta FEG250) a scanning microscope made in the USA, with an accelerating voltage of $20 \mathrm{Kv}$ and a spot size of 3.5 Law vacuum modes. The XRD diffraction patterns of the membranes were acquired using the CubiX3 Diffractometer device.

\subsection{Membranes performance evaluation.}

A simple permeation cell was employed to perform the UF permeation test, as shown in Fig. 1. The HP4750 Stirred Cell is resistant to chemicals, high-pressure, and can perform a broad range of membrane filtrations [34]. The membranes' pure water permeability was evaluated at various pressures ranging from 1 to 5 bar. The volume flow was revealed as follows:

$$
\mathrm{J}_{\mathrm{v}}=\frac{\mathrm{V}}{\mathrm{At}}
$$

whereas $\mathrm{J}$ is the permeation flow $(\mathrm{L} / \mathrm{m} 2 . \mathrm{h}), \mathrm{V}$ is the volume of stored permeate solution (L), The active membrane area (m2) is A, and the period is t. (h) [35]. A stirred cell filtration design connected to a nitrogen gas drum was used to evaluate the dye rejection behavior of the investigated membranes. (stirred HP4750 cell, its diameter of $5.1 \mathrm{~cm} 2$, operating amount of $300 \mathrm{ml}$, operative filtration membrane part of $14.6 \mathrm{~cm} 2$ ) (Figure 1). A dye permeation flux test was performed using $10 \mathrm{ppm}$ of Methylene blue $\mathrm{C} 16 \mathrm{H} 18 \mathrm{CIN} 3 \mathrm{~S}$, whose chemical structure is given in Figure 1 The studies were achieved by performing filtration cycles and collecting (50 $\mathrm{ml}$ ) aliquots of the dye solutions, which were then monitored using an Acculab UVS-90. The rejection was determined by means of a UV-vis spectrophotometer at a wavelength of $2.03 \mathrm{~nm}$ as follows:

$$
\mathrm{R}=\left(1-\frac{\mathrm{C}_{\mathrm{p}}}{\mathrm{C}_{\mathrm{f}}}\right) \times 100 \%
$$

whereas $\mathrm{R}$ is rejection (\%), $\mathrm{Cp}$ and $\mathrm{Cf}$ are concentrations of permeation and feed solutions, respectively.

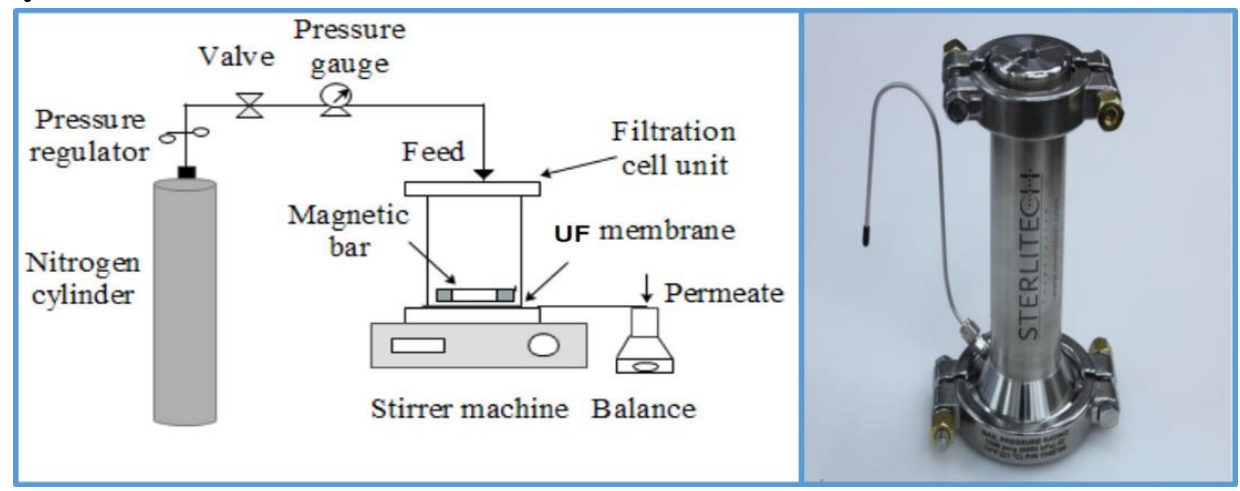

Figure 1. Schematic diagram of UF permeation test unit.

\section{Results and Discussion}

\subsection{Characterization of the nanospheres.}

Mesoporous nanospheres of silica were formed in a basic liquid at ambient temperature with cosolvents ethyl ether, acetone, and water with a quaternary ammonium surfactant 
(CTAB) Cetrimonium bromide. The hydrogen bond among the molecules of water and ethyl ether provides a diffusion path for both surfactant and water to enter the TEOS/ethyl ether oil droplets, promoting the hydrolysis of TEOS polymerizes by means of the surfactant and eventually spheres shaped through soft silica emulsion [36]. Furthermore, acetone has been shown to be a very helpful cosolvent for controlling the nanoparticles morphology and surface roughness, most likely as it is miscible with TEOS and water; thus, rising the acetone percent in the mixed solvent has a tendency to lower TEOS rate hydrolyzation and make the polymerization process of inorganic species more uniform [37]. The usage of acetone as a cosolvent, on the other hand, seems to enhance the reciprocal dissolution of water and ethyl ether, ultimately affecting the structure and morphology of the result. The ethyl ether nanodrops would next be treated with acetone, water, ammonium hydroxide, and CTAB. Hydrolysis/condensation of TEOS and self-assemblage of generated silica species occur simultaneously on the surface and in the interior of ethyl ether nanodroplets when TEOS is introduced to the aforementioned solution after aggressively whirling. When ethyl ether is gasified, extensive mesopores and even macropores develop, resulting in silica nanospheres with a hierarchical porous structure [38]. A significant diffraction peak in the region of 17 to $30^{\circ}$ is seen by X-ray deflection. Fig.6(a), showing typical periodic changes in the electrical density due to the material's long-range ordering of the pores.[29]. The sample for FESEM examination was seen without any metal covering, as presented in Fig.2 (a). A Transmission Microscope (TEM) with excellent resolution was employed for imaging., as presented in Fig.2 (b). The FESEM picture shows $500 \mathrm{~nm}$ nanospheres, whereas the TEM image shows huge slitlike mesopores uniformly dispersed across the nanosphere surface.

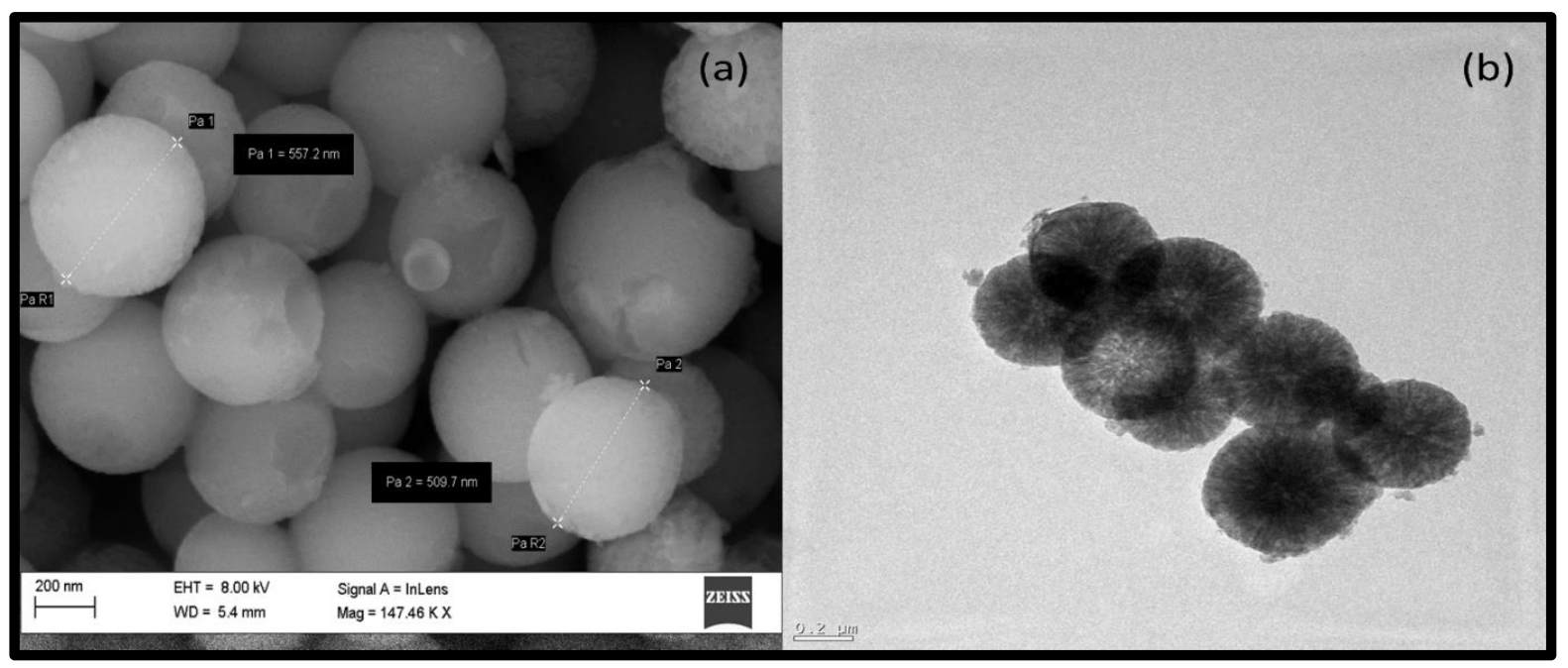

Figure 2. (a) FESEM, and (b) TEM images of the MSNs.

Figure 3a depicts the Isotherms of nitrogen gas adsorption besides desorption for MSNs. Three different adsorption/desorption portions correspond to relative pressures of 0.3 , 0.3-0.9, and 0.9. At desorption portions with high relative pressure values, small and narrow hysteresis loops are noticed. The sorption experiments produced type IV isotherms, which are typical of mesoporous materials [1]. The capillary condensation mechanism in mesopores was connected to the revealed hysteresis loops. The tiny pores with diameters of $3 \mathrm{~nm}$ presented in Figure $3 \mathrm{~b}$ are matching in the typical mesoporous silica templated by CTAB and therefore assigned to the major channel of the composite, whereas a considerable allocation of mesopores with $25 \mathrm{~nm}$ diameters appeared for MSN, signifying the dissolution of superfluous ethyl ether into the CTAB micelle to enlarge [39]. The methylene blue molecule has a minimum molecular 
cross-section of approximately $0.8 \mathrm{~nm}$ and cannot penetrate holes smaller than $1.3 \mathrm{~nm}$ in diameter. [40]. As a result, it can only penetrate bigger micropores (those bigger than $1.3 \mathrm{~nm}$ ), although the majority of it is likely to be absorbed in mesopores. This implies that MSN micropores are mainly bigger pores. As a result, the greater adsorption of MSNs may be attributed to a combination of pore size and surface chemical characteristics. This indicates that increasing the amount of mesoporous silica nanospheres leads to substantial methylene blue rejection.
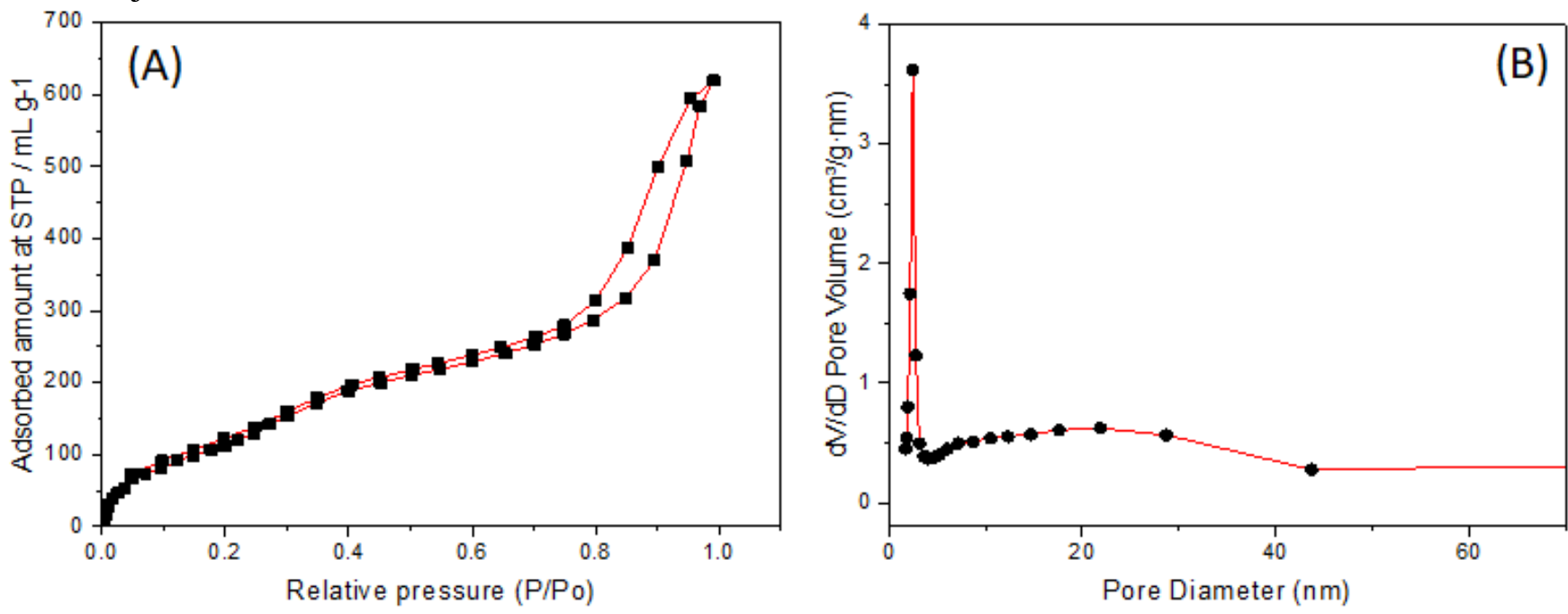

Figure 3. (A) Isotherms of $\mathrm{N}_{2}$ adsorption and desorption and (B) Pore size distribution of MSNs.

\subsection{Characterization of membranes.}

The structure of PSF and nanocomposite PSF membranes may be determined using Xray deflection (XRD). XRD band of MSNs is presented in Fig.4a, with a prominent diffraction crest through a region of 17 to $30^{\circ}$, exposing typical occasional variations of the electronic density because of the long-range ordering of pores in the substance [29]. Figure $4 \mathrm{~b}$ depicts the XRD diffraction image of PS (M0), which showed a wide peak corresponding to the amorphous structure of PSF. Meanwhile, when the concentration of MSNs rises, a strong peak at 2 is seen, which is attributable to the high crystallinity of the MSNs (violet color) - (M4) membrane. This demonstrated that silica may still be found in PS/PVP membranes after mixing and using the phase conversion technique. It also demonstrates that MSNs are spread uniformly throughout the membrane, despite the fact that the proportion utilized is tiny.
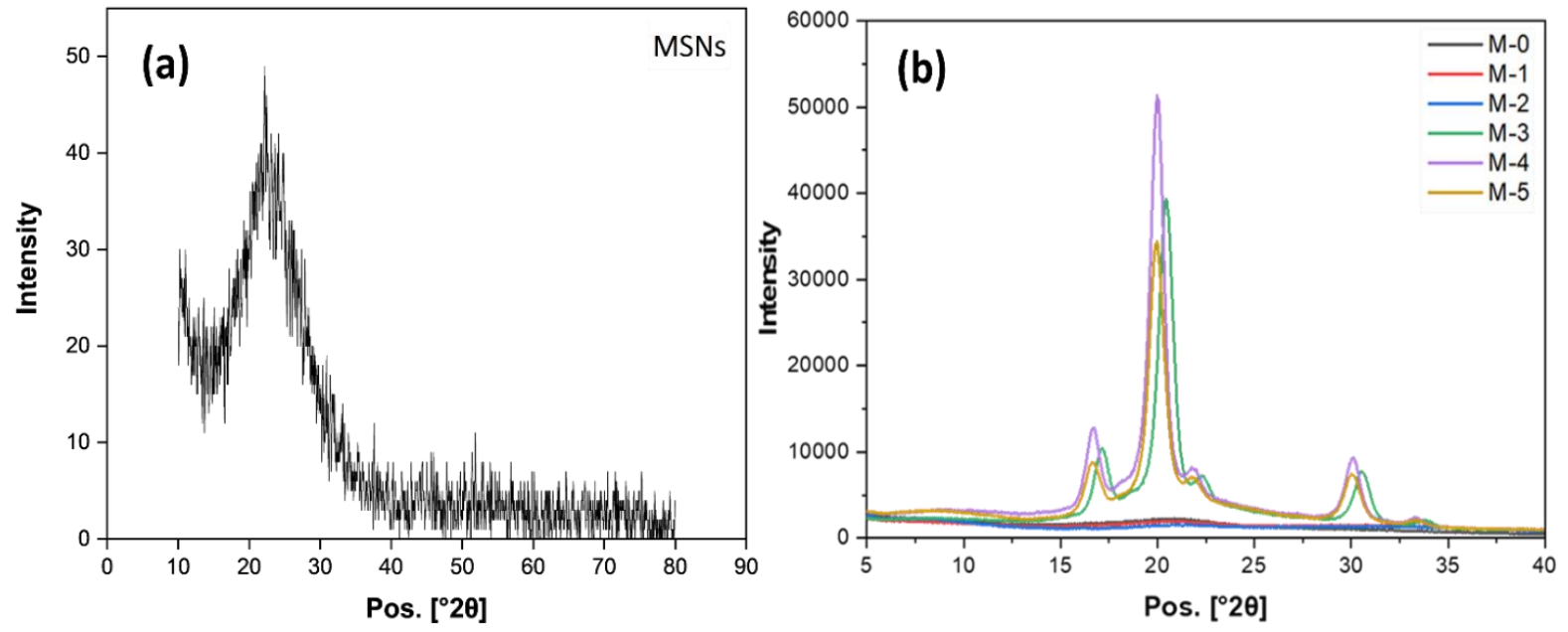

Figure 4. XRD patterns of MSNs (a) and PS/MSNs membranes with different contents of MSNs (b). 
Figure 5 depicts the FT-IR spectral analysis of fabricated membranes because of the inclusion of silica nanospheres, unprecedented peaks at $1106.11 \mathrm{~cm}^{-1}$ and $1080.40 \mathrm{~cm}^{-1}$ emerged in the FT-IR band of membrane samples. The irregular stretching oscillation of $\mathrm{Si}-$ $\mathrm{O}-\mathrm{Si}$ groups was ascribed to these peaks, suggesting the inclusion of $\mathrm{SiO}_{2}$ particles inside membranes [41]. The Si-O-Si regular stretching oscillation is responsible for the absorption peak at $800 \mathrm{~cm}^{-1}$. Si-OH stretching is responsible for the tiny sharp band at $3455.90 \mathrm{~cm}^{-1}$ and $1669.36 \mathrm{~cm}^{-1}$. This demonstrates that $\mathrm{SiO}_{2}$ nanoparticles have more hydrophilic functional groups than pure PS membranes, and as a consequence, the $\mathrm{PS} / \mathrm{PVP} / \mathrm{SiO}_{2}$ nanocomposite membranes are more hydrophilic than pure PS membranes. Two significant absorptions at $1487.79 \mathrm{~cm}^{-1}$ and $1585.35 \mathrm{~cm}^{-1}$ recommend an aromatic vibrational bonding of $\mathrm{C}=\mathrm{C}$ in the polysulfone group, while the wavelength of $2967.88 \mathrm{~cm}^{-1}$ is linked to the vibration of $(=\mathrm{C}-\mathrm{H})$ owing to polysulfone aromatically structure $[42,43]$.

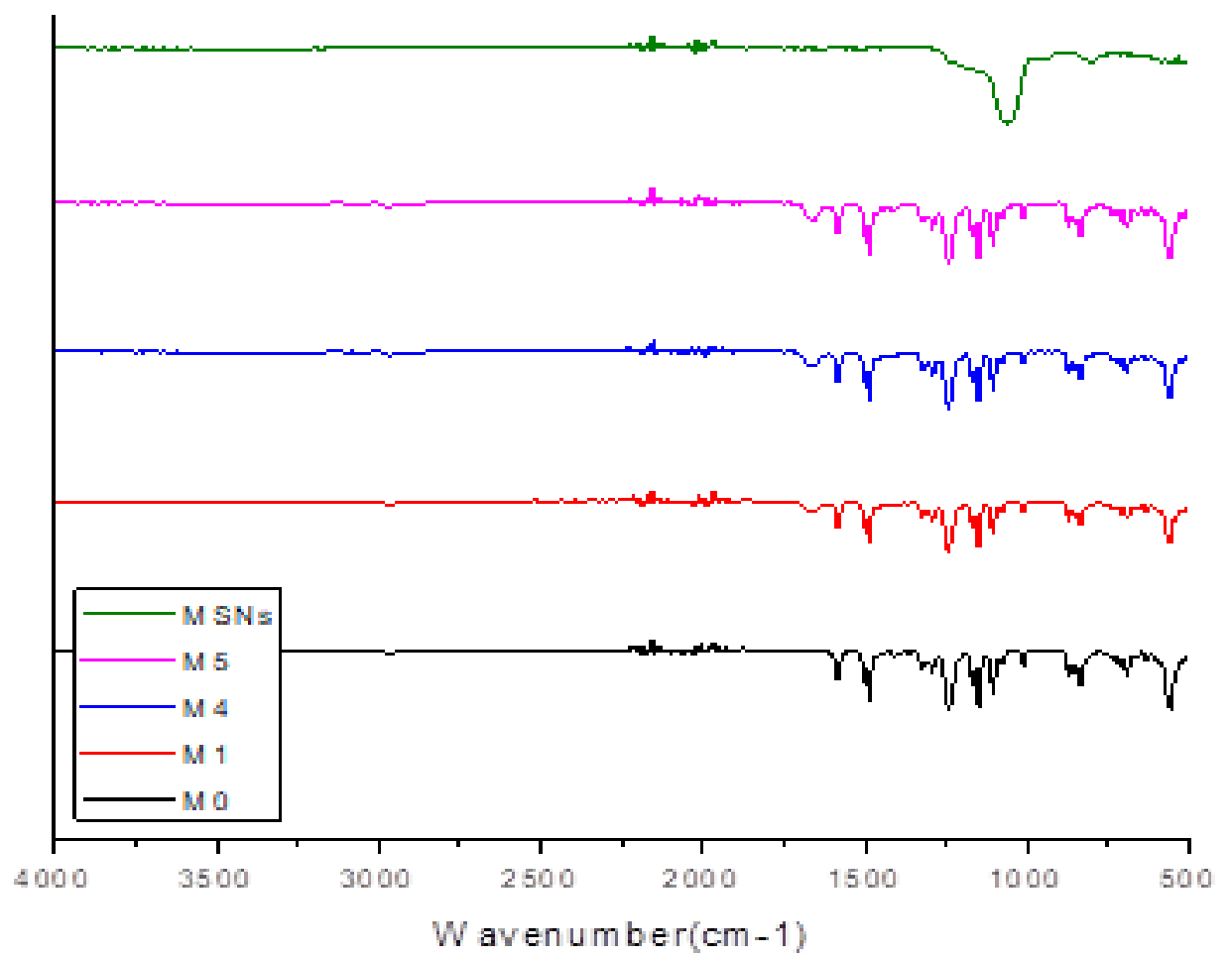

Figure 5. FT-IR spectrum for MSNs, unmodified membrane (M0), and modified membranes.

The surface characteristics of the membrane acquired by SEM imaging are presented in Figure 6, which shows that the addition of a water solvable polymer (PVP) smoothed membrane surface, increasing the hydrophilic nature of pristine PSF membrane [44] (Figure $6 b)$. It was suggested that the addition of additives might be one of the main variables affecting membrane shape and structure [13]. Typically, chemicals are employed to achieve optimum membrane architectures, which leads to improved membrane performance characteristics. The impact of MSNs content on the surface shape and membrane porosity is demonstrated in Figure 6 (c-f), where MSNs were found to be homogeneously distributed along with the internal pores of the polymeric matrix at all concentrations. These findings are contradicted by XRD data (Figure 4), which showed the presence of MSNs in the polymer matrix. SEM examination of top surface morphology indicated that (MSNs blended PS) membranes boasted higher porosity when compared with pristine PS membrane. It was revealed that the porosity of PS/Sio 2 membranes increased owing to two effects:(i) an enlarge in the number of pores; (ii) an enlarge in pore size [45]. SEM surface images revealed that the addition of MSNs to casting solution 
enhanced surface roughness of PSF membrane, which is likely owing to the impaction of nanoparticles on the surface by disrupting the homogeneity of polymeric chains [46]. SEM scans showed a dense layer of crystalline MSNs particles with sizes ranging from 300 to 500 $\mathrm{nm}$ along with the epidermal layer. Compared to other membranes (Figure 6e), M4 membrane had a greater density of nanoscale surface holes.

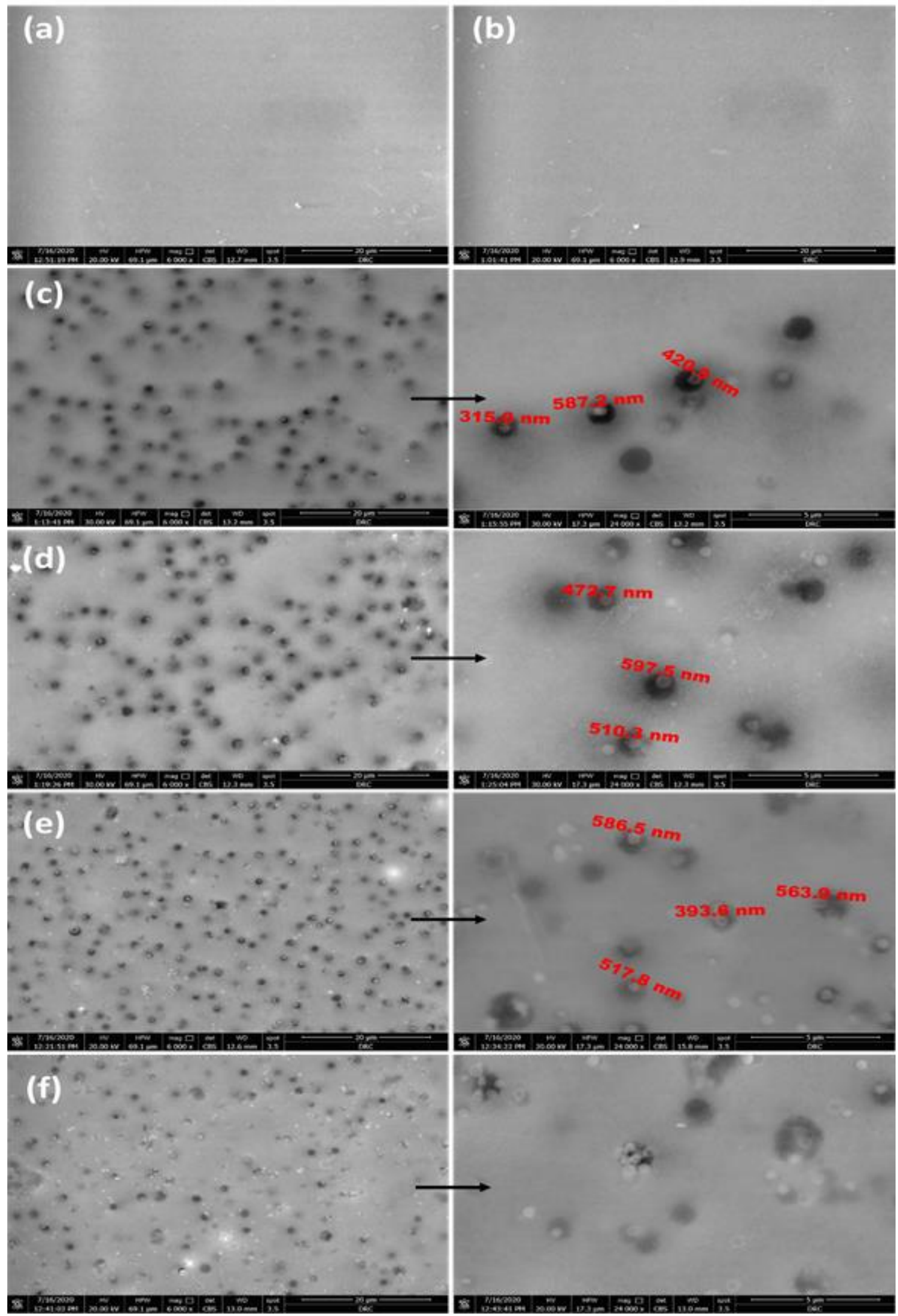

Figure 6. SEM surface images of (a) PSF; (b) PSF/PVP; (c) PSF/PVP/MSNs 2\%; (d) PSF/PVP/MSNs 4\%; (e) PSF/PVP/MSNs 6\%; (f) PSF/PVP/MSNs $8 \%$. 
The SEM cross-section pictures of the membranes are shown in Figure 7. It can be observed that the plain PSF and PSF/PVP membranes have a spongy shape, which may improve separation while decreasing dye rejection [47]. By incorporating MSNs, a finger-like structure and a membrane substructure were altered. Furthermore, macro voids were enlarged, resulting in finger-like structures penetrating the nanoparticles throughout the polymer matrix and enhancing membrane pore interconnectivity [48]. To demonstrate effect of MSNs on internal structure of PSF membranes, it was necessary to show the strategy employed for preparing the porous PS membrane, which included: (a) adjusting the content of polymer in the casting mixture, (b) adjusting the nonsolvent bath temperature, and (c) increasing the content of mesoporous Nano silica spheres. Casting mixture viscosity directly affects the rate of gelation of membranes because the solvent/nonsolvent exchange occurs quicker in littler viscosity mixtures, allowing the production of more porous materials [49]. Visual information of the cross-portion morphology where the thick top layer progressively reduced from $67.24 \mathrm{~m}$ to $37.54 \mathrm{~m}$ was employed to evaluate the impact of MSNs fillers addition on the rheology of the casting solution. The porous sublayer (macro voids) increased from $44.79 \mathrm{~m}$ to $68.05 \mathrm{~m}$, indicating that the macrovoids were grown at low MSNs content and then suppressed at higher content $(6 \mathrm{wt} . \%)$, which could be due to nano-silica particles accommodating on the membrane surface, which caused the formation of a thicker PVP layer.

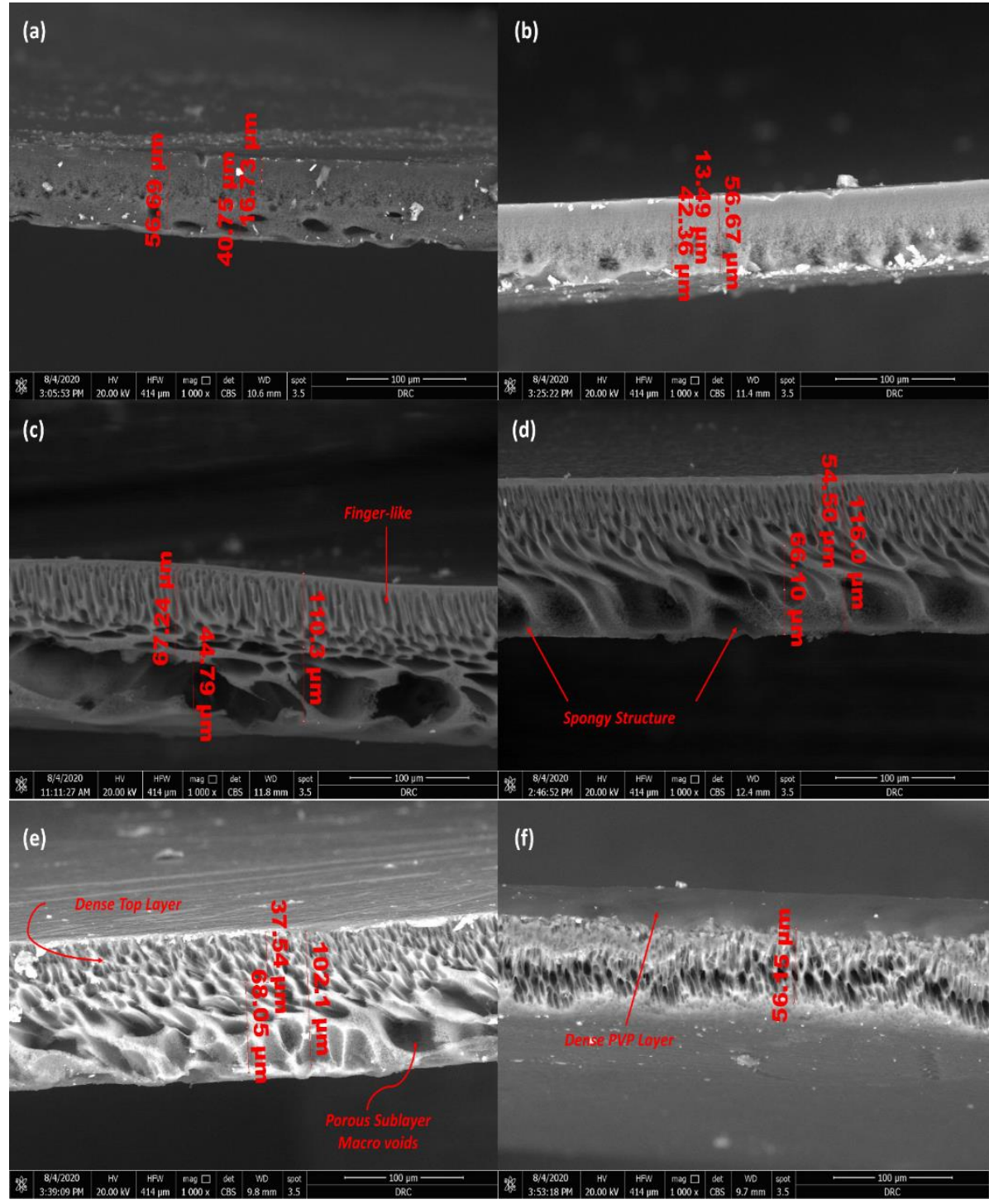

Figure 7. Cross-sectional images of (a) PSF; (b) PSF/PVP; (c) PSF/PVP/MSNs 2\%; (d) PSF/PVP/MSNs 4\%; (e) PSF/PVP/MSNs 6\%; (f) PSF/PVP/MSNs $8 \%$. 
Water tangency angle measurements were shown to decrease as MSNs concentration rose, indicating that the membrane's hydrophilicity improved, potentially improving methylene blue dye rejection. It was discovered that the M4 membrane is extra hydrophilic and serves as a dye barrier, allowing the flow of water molecules through the membrane's pores $[4,50]$. The tangency angle values show that $\mathrm{SiO}_{2}$ nanoparticles contain more hydrophilic functional groups than pure PS membranes, and as a consequence, the $\mathrm{PS} / \mathrm{PVP} / \mathrm{SiO}_{2}$ nanocomposite membranes are more hydrophilic than pure PS membranes [51]. Table 2 shows the impact of the addition of $\mathrm{SiO}_{2}$ nanoparticles on the surface characteristics of $\mathrm{PS} / \mathrm{PVP} / \mathrm{SiO}_{2}$ nanocomposite $\mathrm{UF}$ membranes.

Table 2. Tangency angle of $\mathrm{PS} / \mathrm{PVP} / \mathrm{SiO}_{2}$ membranes with different silica content

\begin{tabular}{c|c|c}
$\begin{array}{c}\text { Membrane } \\
\text { code number }\end{array}$ & $\begin{array}{c}\text { Content of MSNs } \\
\text { (wt. \% PSF) }\end{array}$ & $\begin{array}{c}\text { Tangency angle } \\
\left({ }^{\circ}\right)\end{array}$ \\
\hline M0 & 0 & 96.4 \\
\hline M1 & 0 & 92 \\
\hline M2 & 0.3 & 91.1 \\
\hline M3 & 0.6 & 89 \\
\hline M4 & 0.9 & 84.3 \\
\hline M5 & 1.2 & 82.6
\end{tabular}

\subsection{Membranes performance.}

Permeability of pure water through PSF ultrafiltration prepared membranes at several pressures presented in Fig. 8. As the MSNs concentration of casting solution rose from $\mathrm{M}_{1}$ to $\mathrm{M}_{4}$, it was progressively decreased. It fell from $429.2 \mathrm{~L} / \mathrm{m}^{2} . \mathrm{h}$ for M1 to $136 \mathrm{~L} / \mathrm{m}^{2}$.h for $\mathrm{M}_{4}$. This is because the inclusion of PVP in pure PSF casting solution created a thinner and more porous structure, leading to greater hydraulic permeability. The addition of MSNs changes the pore structure of membranes, either via deposition or by increasing membrane thickness [52]. As the thickness of membrane support grows, the membrane gets denser, and the existence of a sponge-like structure decreases the water permeability rate through membranes. When PVP was introduced to polysulfone membrane, it changed into a highly porous membrane with clear holes [53]. It is known that the addendum of PVP enhances the formation of pores and permeation properties of polysulfone membranes; it is a powerful pore creating agent by giving enough time to performance efficiency of membranes, but MSNs act as fillers, resulting in a decrease in membrane permeability [54].

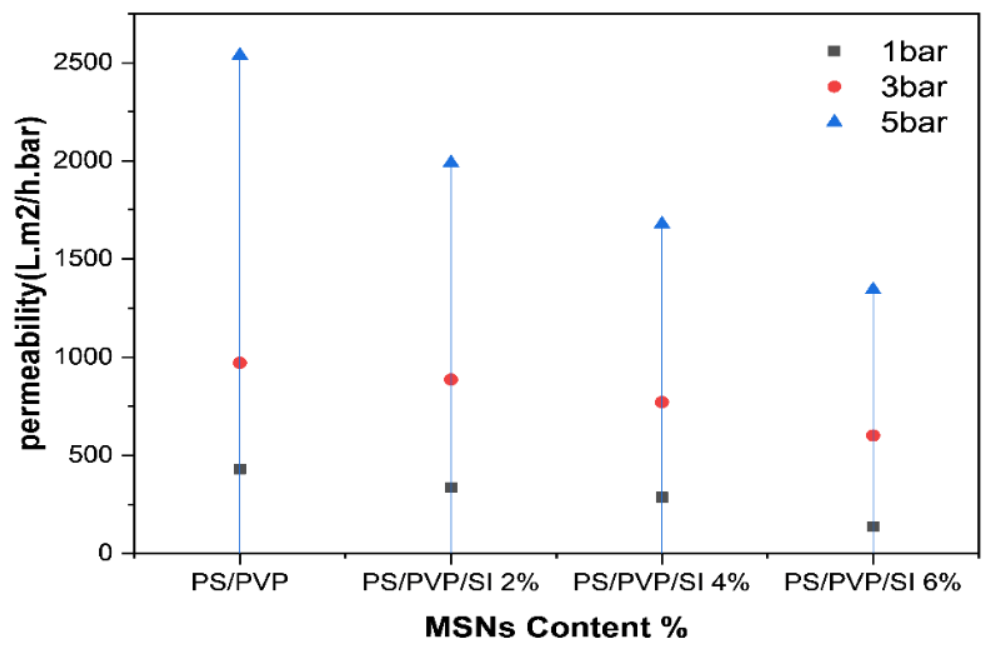

Figure 8. Pure water permeability of the prepared membranes at different pressures as a function of MSNs content. 
Figure 9 shows the rejection of Methylene blue $\mathrm{C}_{16} \mathrm{H}_{18} \mathrm{ClN}_{3} \mathrm{~S}$ by manufactured nanocomposite membranes, including various amounts of $\mathrm{SiO}_{2}$ nanoparticles and the pure Polysulfone membrane. As a result, the percentage of Methylene blue rejection for $\mathrm{M}_{0}$ to $\mathrm{M}_{5}$ membranes was 43.74, 46.03, 58.92, 80.34, 84.73, and 51.92 \%, respectively, demonstrating that all $\mathrm{PS} / \mathrm{PVP} / \mathrm{SiO}_{2}$ membranes had higher rejection efficiency than pure PS membranes. Furthermore, rejection of Methylene blue by nanocomposite membranes increased due to increasing $\mathrm{SiO}_{2}$ nanoparticles. Thus, the greatest rejection efficiency was achieved with about $85 \%$ separation efficiency, although the M4 membrane showed less clean water flow than others. Size exclusion (sieving, steric effect), electrostatic discharges (electrical, Donnan), and adsorption on membrane surface may all be employed to remove organic molecules (in this case, Methylene blue) via modified membranes [55]. The separation efficiency may be increased due to pore blockage or narrowing caused by the precipitation of contaminant molecules. These processes are typically determined by the pollutant's physicochemical qualities, solubility conditions, membrane features, and operational circumstances. The methylene blue molecule has a minimum molecular cross-section of approximately $0.8 \mathrm{~nm}$ and cannot penetrate holes smaller than $1.3 \mathrm{~nm}$ in diameter. As a result, it can only penetrate bigger micropores (those larger than $1.3 \mathrm{~nm}$ ), although most of it is likely to be absorbed in mesopores. This indicates that MSN micropores are mainly bigger pores, as shown by MSN nitrogen adsorption/desorption isotherms. As a result, the absorption mechanism has a substantial impact on separation efficiency. The size exclusion mechanism may partly prevent methylene blue molecules from passing through membrane holes. As can be observed, although the dye rejection progressively rose with increasing MSNs concentration, the permeate flow was found to decrease. Water flow gradually decreases from 183.1, 164.3, 146.2, 135.4, 111.2, and 113.3 $\mathrm{L} / \mathrm{m}^{2} . \mathrm{h}$ for $\mathrm{M}_{0}$ to $\mathrm{M}_{5}$ membranes. Increasing the casting mixture viscosity by adding additional $\mathrm{SiO}_{2}$ nanoparticles ( $6 \% \mathrm{wt}$ ) progressively reduces the quantity of solvent (DMF) / nonsolvent (water) exchange, resulting in a delayed phase separation action [56]. As a result, the creation or growth of macro voids in the membrane is inhibited. As a result, the system develops smaller holes, membrane sponge structure grows, and membrane flux diminishes $\left(\mathrm{M}_{4}\right)$. Figure 7 shows cross-sectional pictures of the manufactured membranes. As can be observed, the pure PSF membrane has a denser and more compact surface than membranes treated with $\mathrm{SiO}_{2}$ nanoparticles, which may decrease water flow and hence permeability.

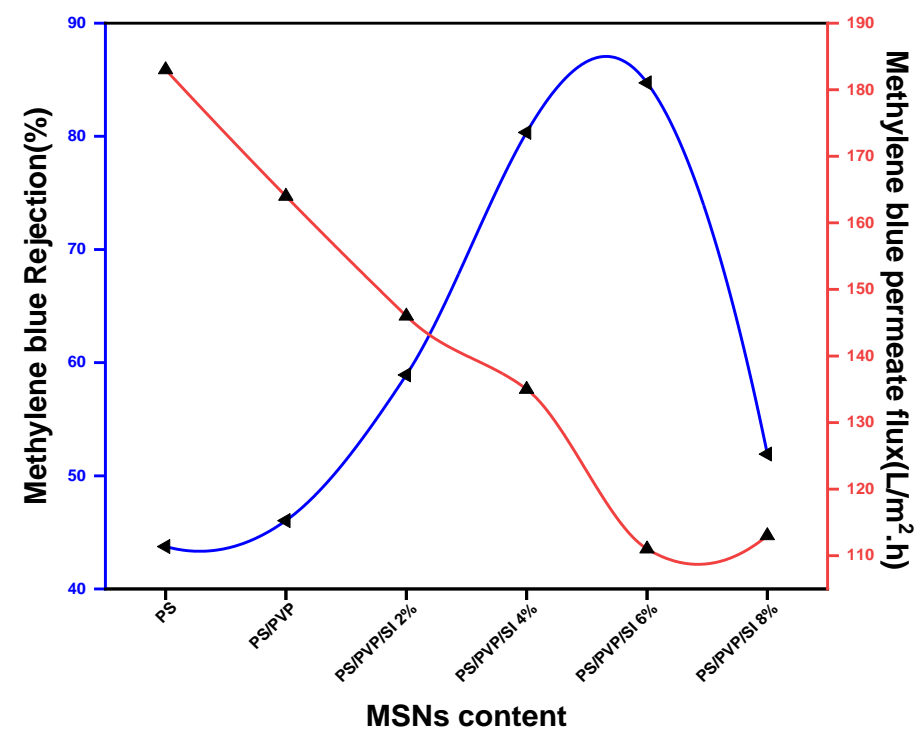

Figure 9. Rejection of Methylene blue and permeation flux of PS, PS/PVP/SiO 2 hybrid membranes as a function of MSNs concentration (Pressure= 1 bar, Methylene blue concentration=10ppm). 
Two samples of industrial wastewater were brought to check the saturation of the membrane and test its efficiency in practice, the first from a ceramic factory in the industrial zone in the northwestern Gulf of Suez. The second from a textile dyeing factory in the Delta region, where samples were prepared as follows: The first sample, coded as $(\mathrm{C})$, is an industrial drainage sample from ceramic factories where we notice the presence of large quantities of mixed soil with the colors of tile and glaze used for polishing, so the sample was left for sedimentation for 48 hours, then a filter was made using several layers of cloth to separate the dust from the sample and then left for another 48 hours for sedimentation. The remaining was separated from extremely fine dust using filter paper, and the appearance of a light blue hue with a blank absorption of $296 \mathrm{~nm}$ was noted. Filtration and sample preparation for separation was completed. The membranes were evaluated in a constructed cell under 1 bar pressure, and the percentage of dye rejection for membranes $M_{1}$ and $M_{4}$ was $39.17 \%$ and $72.15 \%$, respectively, with a reduction in water flow from 176.84 to $123.66 \mathrm{~L} / \mathrm{m}^{2} . h$. The second sample, a textile factory industrial sample coded as (T), was filtered using filter paper to ensure that impurities and remnants of the tissue were removed, to observe the purity of the purple color, and to prepare the sample for separation by repeating the previous steps using the cell at a pressure of 1 bar with a blank absorption of $300 \mathrm{~nm}$. A membrane with high dye rejection is needed to treat textile effluent properly. The membranes were evaluated in the manufactured cell, and the percentage of dye rejection for membranes $\mathrm{M}_{1}$ and $\mathrm{M}_{4}$ was $53.12 \%$ and $93.2 \%$, respectively, with a reduction in water flow from 156.17 to $100.61 \mathrm{~L} / \mathrm{m}^{2} / \mathrm{h}$. This research indicates that applying nanocomposite membranes to remove contaminants such as dyes from industrial wastewater resources is promising.
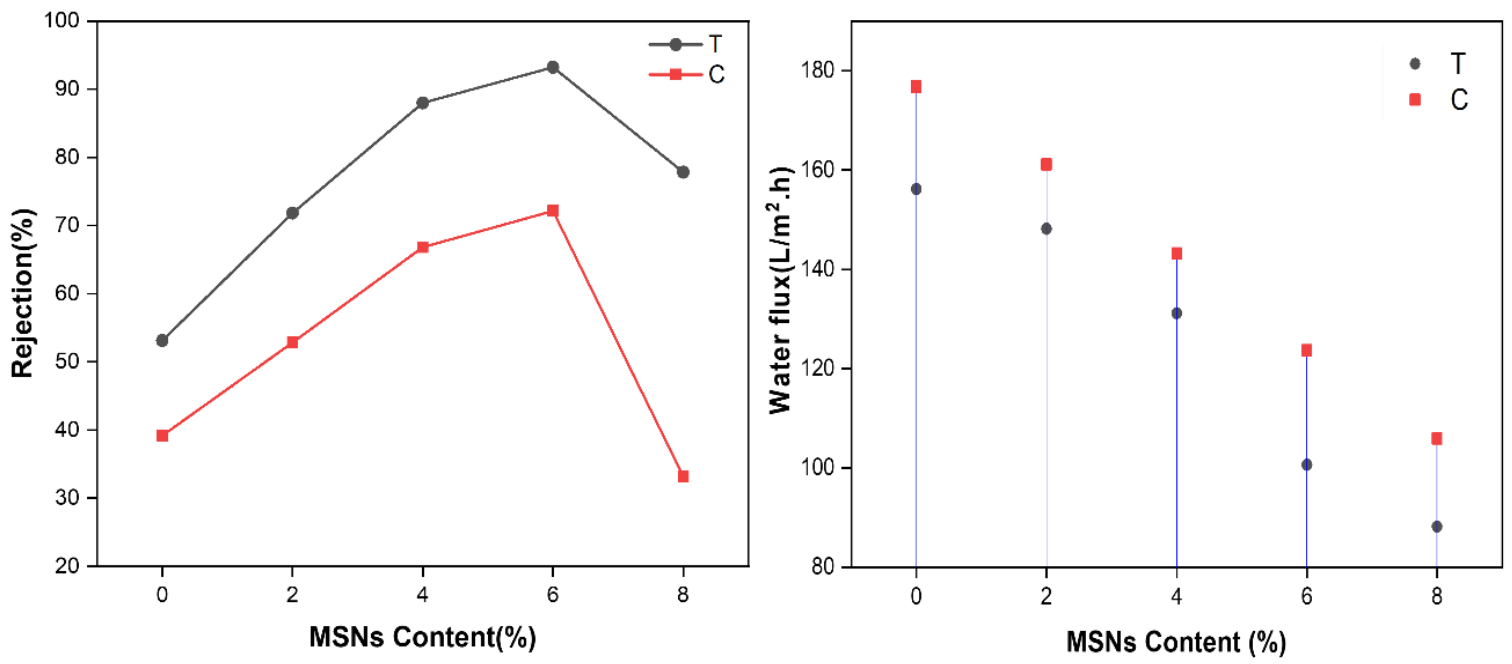

Figure 10. Rejection and water flux of industrial wastewater sample through hybrid membranes as a function of MSNs concentration.

\section{Conclusions}

The phase conversion technique, which included the direct addition of MSNs to the casting solution, was employed to create PS membranes containing MSNs nanoparticles. MSNs substantially enhanced the hydrophilic property and permeability of membranes because of the existence of oxygen-containing groups. The hydrophilicity of $\mathrm{PS} / \mathrm{PVP} / \mathrm{SiO}_{2}$ membranes was verified by lowering the water tangency angle. When MSNs are introduced, the asymmetric structure of the membrane changes from a sponge-shaped form with closed-end tear-like holes to a porous finger-like structure with open-end channels, as presented by cross- 
sectional pictures. According to SEM surface images, surface roughness increased as the MSNs concentration in polymer solution rose. The concentration of MSNs nanoparticles, according to the results of this research, is an essential parameter that may influence the function and shape of membranes. Due to dye permeate flux characteristics and rejection qualities, the optimum MSNs concentration in casting solution was found at $6 \mathrm{wt}$. percent. The rejection of methylene blue by produced nanocomposite membranes was also substantially enhanced. As the content of MSNs rose, so did the rate of Methylene blue retention. Because of its hydrophilic characteristics and high rejection effectiveness, the findings of this research showed that the mixed matrix membrane modified with MSNs might offer acceptable results in practical applications. According to the results of this research, PS has been verified as a potential polymeric material, owing to its asymmetric structure shown by the phase conversion method. PVP has long been acknowledged as a better pore former when compared to other additives. The addition of $6 \%$ MSNs particles improved porosity, selectivity, and continuity of the membrane ultrafiltration process. Consequently, this research contributes substantially to contemporary information and wastewater treatment, mainly for the dyes sector.

\section{Funding}

This research received no external funding.

\section{Acknowledgments}

My thanks are due to both Suez Univerisity and Suez International Nitrate Company (SINCO) for providing me an opportunity to do a significant part of my research in Suez In partnership with Desert Research Center

\section{Conflicts of Interest}

The authors declare that they have no known competing financial interests or personal relationships that could have influenced the work reported in this paper.

\section{References}

1. Mollahosseini, A.; Rahimpour, A.; Jahamshahi, M.; Peyravi, M.; Khavarpour, M. The effect of silver nanoparticle size on performance and antibacteriality of polysulfone ultrafiltration membrane. Desalination 2012, 306, 41-50, https://doi.org/10.1016/j.desal.2012.08.035.

2. Saravanan, A.; Kumar, P.S.; Jeevanantham, S.; Karishma, S.; Tajsabreen, B.; Yaashikaa, P.; Reshma, B.J.C. Effective water/wastewater treatment methodologies for toxic pollutants removal: Processes and applications towards sustainable development. Chemosphere 2021, 280, 130595 , https://doi.org/10.1016/j.chemosphere.2021.130595.

3. Koutahzadeh, N.; Esfahani, M.R.; Arce, P.E. Sequential Use of UV/H2O2-(PSF/TiO2/MWCNT) Mixed Matrix Membranes for Dye Removal in Water Purification: Membrane Permeation, Fouling, Rejection, and Decolorization. Environmental Engineering Science 2016, 33, 430-440, https://doi.org/10.1089/ees.2016.0023.

4. Mozia, S.; Tomaszewska, M.; Morawski, A.W. Photocatalytic membrane reactor (PMR) coupling photocatalysis and membrane distillation-Effectiveness of removal of three azo dyes from water. Catalysis Today 2007, 129, 3-8, https://doi.org/10.1016/j.cattod.2007.06.043.

5. Abdel-Fatah, M.A.; Amin, A.; Elkady, H. Industrial wastewater treatment by membrane process. In Membrane-Based Hybrid Processes for Wastewater Treatment 2021, 341-365, https://doi.org/10.1016/B978-0-12-823804-2.00025-2.

6. Huang, C.J.; Yang, B.M.; Chen, K.S.; Chang, C.C.; Kao, C.M. Application of membrane technology on semiconductor wastewater reclamation: A pilot-scale study. Desalination 2011, 278, 203-210, https://doi.org/10.1016/j.desal.2011.05.032. 
7. Guo, W.; Ngo, H.-H.; Li, J. A mini-review on membrane fouling. Bioresource Technology 2012, 122, 27-34, https://doi.org/10.1016/j.biortech.2012.04.089.

8. Chakrabarty, B.; Ghoshal, A.K.; Purkait, M.K. Ultrafiltration of stable oil-in-water emulsion by polysulfone membrane. Journal of Membrane Science 2008, 325, 427-437, https://doi.org/10.1016/j.memsci.2008.08.007.

9. Benkhaya, S.; Lgaz, H.; Alrashdi, A.A.; M'rabet, S.; El Bachiri, A.; Assouag, M.; Chung, I.-M.; El Harfi, A.J.J.o.M.L. Upgrading the performances of polysulfone/polyetherimide ultrafiltration composite membranes for dyes removal: Experimental and molecular dynamics studies. 2021, 331, 115743, https://doi.org/10.1016/j.molliq.2021.115743.

10. Benkhaya, S.; Lgaz, H.; Alrashdi, A.A.; M'Rabet, S.; El Bachiri, A.; Assouag, M.; Chung, I.-M.; El Harfi, A. Upgrading the performances of polysulfone/polyetherimide ultrafiltration composite membranes for dyes removal: Experimental and molecular dynamics studies. Journal of Molecular Liquids 2021, 331, 115743, https://doi.org/10.1016/j.molliq.2021.115743.

11. Heidi Lynn, R.; Priscilla GL, B.; Emmanuel, I.J.J.o.S.E.M.; Technology, A. Metal nanoparticle modified polysulfone membranes for use in wastewater treatment: a critical review. 2012, 2012, https://doi.org/10.4236/jsemat.2012.223029.

12. Habibi, S.; Nematollahzadeh, A.; Mousavi, S.A. Nano-scale modification of polysulfone membrane matrix and the surface for the separation of chromium ions from water. Chemical Engineering Journal 2015, 267, 306-316, https://doi.org/10.1016/j.cej.2015.01.047.

13. Chakrabarty, B.; Ghoshal, A.K.; Purkait, M.K. Effect of molecular weight of PEG on membrane morphology and transport properties. Journal of Membrane Science 2008, 309, 209-221, https://doi.org/10.1016/j.memsci.2007.10.027.

14. Zhao, C.; Xue, J.; Ran, F.; Sun, S. Modification of polyethersulfone membranes - A review of methods. Progress in Materials Science 2013, 58, 76-150, https://doi.org/10.1016/j.pmatsci.2012.07.002.

15. Chakrabarty, B.; Ghoshal, A.K.; Purkait, M.K. Preparation, characterization and performance studies of polysulfone membranes using PVP as an additive. Journal of Membrane Science 2008, 315, 36-47, https://doi.org/10.1016/j.memsci.2008.02.027.

16. Han, M.-J.; Nam, S.-T. Thermodynamic and rheological variation in polysulfone solution by PVP and its effect in the preparation of phase inversion membrane. Journal of Membrane Science 2002, 202, 55-61, https://doi.org/10.1016/S0376-7388(01)00718-9.

17. Zhao, W.; Huang, J.; Fang, B.; Nie, S.; Yi, N.; Su, B.; Li, H.; Zhao, C. Modification of polyethersulfone membrane by blending semi-interpenetrating network polymeric nanoparticles. Journal of Membrane Science 2011, 369, 258-266, https://doi.org/10.1016/j.memsci.2010.11.065.

18. Aerts, P.; Genne, I.; Kuypers, S.; Leysen, R.; Vankelecom, I.F.J.; Jacobs, P.A. Polysulfone-aerosil composite membranes: Part 2. The influence of the addition of aerosil on the skin characteristics and membrane properties. Journal of Membrane Science 2000, 178, 1-11, https://doi.org/10.1016/S0376-7388(00)00428-2.

19. Aerts, P.; Van Hoof, E.; Leysen, R.; Vankelecom, I.F.J.; Jacobs, P.A. Polysulfone-Aerosil composite membranes: Part 1. The influence of the addition of Aerosil on the formation process and membrane morphology. Journal of Membrane Science 2000, 176, 63-73, https://doi.org/10.1016/S0376-7388(00)004270 .

20. Fan, Z.; Wang, Z.; Sun, N.; Wang, J.; Wang, S. Performance improvement of polysulfone ultrafiltration membrane by blending with polyaniline nanofibers. Journal of Membrane Science 2008, 320, 363-371, https://doi.org/10.1016/j.memsci.2008.04.019.

21. Qiu, S.; Wu, L.; Pan, X.; Zhang, L.; Chen, H.; Gao, C. Preparation and properties of functionalized carbon nanotube/PSF blend ultrafiltration membranes. Journal of Membrane Science 2009, 342, 165-172, https://doi.org/10.1016/j.memsci.2009.06.041.

22. Razmjou, A.; Mansouri, J.; Chen, V. The effects of mechanical and chemical modification of TiO2 nanoparticles on the surface chemistry, structure and fouling performance of PES ultrafiltration membranes. Journal of Membrane Science 2011, 378, 73-84, https://doi.org/10.1016/j.memsci.2010.10.019.

23. Taurozzi, J.; Arul, H.; Bosak, V.; Burban, A.; Voice, T.; Bruening, M.; Tarabara, V. Effect of filler incorporation route on the properties of polysulfone-silver nanocomposite membranes of different porosities. Journal of Membrane Science 2008, 325, 58-68, https://doi.org/10.1016/j.memsci.2008.07.010.

24. Yang, Y.; Zhang, H.; Wang, P.; Zheng, Q.; Li, J. The influence of nano-sized TiO2 fillers on the morphologies and properties of PSF UF membrane. Journal of Membrane Science 2007, 288, 231-238, https://doi.org/10.1016/j.memsci.2006.11.019.

25. Sotto, A.; Boromand, A.; Zhang, R.; Luis, P.; Arsuaga, J.M.; Kim, J.; Van der Bruggen, B. Effect of nanoparticle aggregation at low concentrations of $\mathrm{TiO} 2$ on the hydrophilicity, morphology, and fouling resistance of PES-TiO2 membranes. Journal of Colloid and Interface Science 2011, 363, 540-550, https://doi.org/10.1016/j.jcis.2011.07.089.

26. Sun, M.; Su, Y.; Mu, C.; Jiang, Z. Improved Antifouling Property of PES Ultrafiltration Membranes Using Additive of Silica-PVP Nanocomposite. Industrial \& Engineering Chemistry Research 2010, 49, 790-796, https://doi.org/10.1021/ie900560e. 
27. Shahat, A.; Hassan, H.M.; El-Shahat, M.; El Shahawy, O.; Awual, M.R.J.N.J.o.C. A ligand-anchored optical composite material for efficient vanadium (II) adsorption and detection in wastewater. 2019, 43, 1032410335, https://doi.org/10.1039/C9NJ01818B.

28. Selvarajan, V.; Obuobi, S.; Ee, P.L.R.J.F.i.c. Silica Nanoparticles-A Versatile Tool for the Treatment of Bacterial Infections. 2020, 8, 602, https://doi.org/10.3389/fchem.2020.00602.

29. Kioni, P.N.; Gao, Y.; Tang, Z.; Gatebe, E.; Wanyika, H. Synthesis and characterization of ordered mesoporous silica nanoparticles with tunable physical properties by varying molar composition of reagents. 2011, https://doi.org/10.5897/AJPP11.592.

30. Shahat, A.; Trupp, S. Sensitive, selective, and rapid method for optical recognition of ultra-traces level of $\mathrm{Hg}(\mathrm{II}), \mathrm{Ag}(\mathrm{I}), \mathrm{Au}(\mathrm{III})$, and $\mathrm{Pd}(\mathrm{II})$ in electronic wastes. Sensors and Actuators B: Chemical 2017, 245,789802, https://doi.org/10.1016/j.snb.2017.02.008.

31. Alkindy, M.B.; Naddeo, V.; Banat, F.; Hasan, S.W.J.W.S.; Technology. Synthesis of polyethersulfone (PES)/GO-SiO2 mixed matrix membranes for oily wastewater treatment. 2020, 81, 1354-1364, https://doi.org/10.2166/wst.2019.347.

32. Aktas Eken, G.; Acar, M.H.J.J.o.A.P.S. Polysulfone-based amphiphilic copolymers: Effect of hydrophilic content on morphology and performance of ultrafiltration membranes. Journal of Applied Polimer science 2020, 137, 48306, https://doi.org/10.1002/app.48306.

33. Stalder, A.F.; Kulik, G.; Sage, D.; Barbieri, L.; Hoffmann, P. A. snake-based approach to accurate determination of both contact points and contact angles. Colloids and Surfaces A: Physicochemical and Engineering Aspects 2006, 286, 92-103, https://doi.org/10.1016/j.colsurfa.2006.03.008.

34. Alhumaidi, M.S.; Arshad, F.; Aubry, C.; Ravaux, F.; McElhinney, J.; Hasan, A.; Zou, L.J.N. Electrostatically coupled $\mathrm{SiO} 2$ nanoparticles/poly (L-DOPA) antifouling coating on a nanofiltration membrane. 2020, 31, 275602, https://doi.org/10.1088/1361-6528/ab8085.

35. Matsuyama, H.; Maki, T.; Teramoto, M.; Kobayashi, K. Effect of PVP Additive on Porous Polysulfone Membrane Formation by Immersion Precipitation Method. Separation Science and Technology 2003, 38, 3449-3458, https://doi.org/10.1081/SS-120023408.

36. Chang, C.-L.; Fogler, H.S.J.L. Controlled formation of silica particles from tetraethyl orthosilicate in nonionic water-in-oil microemulsions. 1997, 13, 3295-3307, https://doi.org/10.1021/la961062z.

37. Zhang, J.; Liu, M.; Zhang, A.; Lin, K.; Song, C.; Guo, X.J.S.s.s. Facile synthesis of mesoporous silica nanoparticles with controlled morphologies using water-acetone media. Solid State Sciences 2010, 12, 267273, https://doi.org/10.1016/j.solidstatesciences.2009.11.005.

38. Du, X.; He, J.J.L. Fine-tuning of silica nanosphere structure by simple regulation of the volume ratio of cosolvents. 2010, 26, 10057-10062, https://doi.org/10.1021/la100196j.

39. Gu, F.N.; Lin, W.G.; Yang, J.Y.; Wei, F.; Wang, Y.; Zhu, J.H.J.M.; Materials, M. Fabrication of centimetersized sphere of mesoporous silica with well-defined hollow nanosphere topology and its high performance in adsorbing phenylalanine. Microporus and Mesoporus Materials 2012, 151, 142-148, https://doi.org/10.1016/J.MICROMESO.2011.11.001.

40. Valdés, H.; Sánchez-Polo, M.; Rivera-Utrilla, J.; Zaror, C.J.L. Effect of ozone treatment on surface properties of activated carbon. 2002, 18, 2111-2116, https://doi.org/10.1021/la010920a.

41. El Shafei, G.M.; Mokhtar, M.J.C.; Physicochemical, S.A.; Aspects, E. Interaction between molybdena and silica: FT-IR/PA studies of surface hydroxyl groups and pore structure assessment. Colloids and Surfaces A:Physicochemical and Engineering Aspects 1995, 94, 267-277, https://doi.org/10.1016/09277757(94)03005-7.

42. Shakak, M.; Rezaee, R.; Maleki, A.; Jafari, A.; Safari, M.; Shahmoradi, B.; Daraei, H.; Lee, S.-M.J.E.T.; Innovation. Synthesis and characterization of nanocomposite ultrafiltration membrane (PSF/PVP/SiO2) and performance evaluation for the removal of amoxicillin from aqueous solutions. Environmental Technology \& Innovation 2020, 17, 100529, https://doi.org/10.1016/j.eti.2019.100529.

43. Nasirian, D.; Salahshoori, I.; Sadeghi, M.; Rashidi, N.; Hassanzadeganroudsari, M.J.P.B. Investigation of the gas permeability properties from polysulfone/polyethylene glycol composite membrane. Springer 2020, 77, 5529-5552, https://doi.org/10.1007/s00289-019-03031-3.

44. Van Tran, T.T.; Kumar, S.R.; Nguyen, C.H.; Lee, J.W.; Tsai, H.-A.; Hsieh, C.-H.; Lue, S.J.J.J.o.M.S. Highpermeability graphene oxide and poly (vinyl pyrrolidone) blended poly (vinylidene fluoride) membranes: Roles of additives and their cumulative effects. Journal of Membranes Sciences 2021, 619, 118773, https://doi.org/10.1016/j.memsci.2020.118773.

45. Rambabu, K.; Velu, S. Modified cellulose acetate ultrafiltration composite membranes for enhanced dye removal. Int. J. Chem. Sci 2016, 14, 195-205, https:/www.tsijournals.com/abstract/modified-celluloseacetate-ultrafiltration-composite-membranes-for-enhanced-dye-removal-10249.html.

46. de Moura, M.R.; Mattoso, L.H.C.; Zucolotto, V. Development of cellulose-based bactericidal nanocomposites containing silver nanoparticles and their use as active food packaging. Journal of Food Engineering 2012, 109, 520-524, https://doi.org/10.1016/j.jfoodeng.2011.10.030.

47. Hassan, A.R.; Rozali, S.; Safari, N.H.M.; Besar, B.H. The roles of polyethersulfone and polyethylene glycol additive on nanofiltration of dyes and membrane morphologies. Environmental Engineering Research 2018, 23, 316-322, https://doi.org/10.4491/eer.2018.023. 
48. Sarkar, S.; Chakraborty, S.J.G.f.S.D. Nanocomposite polymeric membrane a new trend of water and wastewater treatment: A short review. 2020, 100533, https://doi.org/10.1016/j.gsd.2020.100533.

49. Boussu, K.; Vandecasteele, C.; Van der Bruggen, B.J.P. Study of the characteristics and the performance of self-made nanoporous polyethersulfone membranes. Polymer 2006, 47, 3464-3476, https://doi.org/10.1016/j.polymer.2006.03.048.

50. Gryta, M.; Tomaszewska, M.; Grzechulska - Damszel, J.; Morawski, A. Membrane distillation of $\mathrm{NaCl}$ solution containing natural organic matter. Journal of Membrane Science 2001, 181, 279-287, https://doi.org/10.1016/S0376-7388(00)00582-2.

51. Li, X.; Janke, A.; Formanek, P.; Fery, A.; Stamm, M.; Tripathi, B.P.J.M.T.C. High permeation and antifouling polysulfone ultrafiltration membranes with in situ synthesized silica nanoparticles. Materials Today Communications 2020, 22, 100784, https://doi.org/10.1016/j.mtcomm.2019.100784.

52. Tewfik, S.R.; Sorour, M.H.; Abulnour, A.M.; Shaalan, H.F.; Hani, H.A.; El-Sayed, M.M.; Abdelrahman, Y.O.; Sayed, E.S.; Mohamed, A.N.; Al-Mansoup, A.A. Membrane Materials Design Trends: Nanoadditives. In Membrane Desalination CRC Press: 2020;.17-64, https://doi.org/10.1201/9780429020254.

53. Ponnaiyan, P.; Nammalvar, G.J.P.B. Enhanced performance of PSF/PVP polymer membrane by silver incorporation 2020, 77, 197-212, https://doi.org/10.1007/s00289-019-02735-w.

54. Sunil, K.; Prajwal, S.; Rao, S.; Lavanya, C.; Balakrishna, G.R.; Arthanareeswaran, G.; Padaki, M.J.J.o.E.C.E. Prolific approach for the removal of dyes by an effective interaction with polymer matrix using ultrafiltration membrane. 2021, 106328, https://doi.org/10.1016/j.jece.2021.106328.

55. Zhang, Y.; Zhou, S.; Li, Z.; Zhang, H.; Zhang, M.; Wang, J.; Chen, L.; Zhang, H.J.J.o.M.S. Effect of poreforming/hydrophilic additive anchorage on the mesoporous structure and sieving performance of a blended ultrafiltration (UF) membrane. 2021, 119904, https://doi.org/10.1016/j.memsci.2021.119904.

56. Saljoughi, E.; Mousavi, S.M.J.S.; technology, p. preparation and characterization of novel polysulfone nanofiltration membranes for removal of cadmium from contaminated water. 2012, 90, 22-30, https://doi.org/10.1016/j.seppur.2012.02.008. 